\title{
Comparing clinical outcomes of connective tissue grafts to platelet rich fibrin in gingival recession treatment - an extended case series
}

\author{
SADJ November 2019, Vol. 74 No. 10 p538 - p548 \\ F Peer ${ }^{1}$, GU Mohangi ${ }^{2}$
}

\section{SUMMARY}

\section{Aim}

To appraise clinical and aesthetic outcomes of connective tissue grafts (CTG) and platelet rich fibrin (PRF) in managing marginal gingival recession.

\section{Methods and materials}

Five patients each with at least two contralateral Miller's Class I and/or Class II recession lesions underwent treatment in a case series with a randomised split-mouth design. Each site was paired with a similar contralateral lesion and randomly assigned to the CTG (control) or PRF (test) treatment.

Probing depth, recession depth, recession width, clinical attachment level, keratinised tissue width and gingival thickness were recorded and the data compared. Photographs were taken at baseline and at 24-weeks to evaluate aesthetics using the Pink Esthetic Score (PES). A questionnaire was used to assess patient satisfaction with treatment outcomes.

\section{Results and conclusions}

Both treatment options resulted in improved clinical measurements but CTGs demonstrated improvements at a greater number of sites than PRF $(60 \%$ to $30 \%$ respectively).

\section{Author affiliations:}

1. Fatima Peer: BDS MSc Dent Wits), Department of Oral Medicine \& Periodontology, School of Oral Health Sciences, Faculty of Health Science, University of the Witwatersrand, Parktown, Johannesburg.

ORCID Number: 0000-0002-5542-4949

2. Govindrau U Mohangi: BDS (Mys), DipOdont-Perio, DipOdontOral Med, MScOdont-Perio, MChD-OMP (Pret), Specialist in Oral Medicine \& Periodontics Department of Oral Medicine \& Periodontology, School of Oral Health Sciences, Faculty of Health Science, University of the Witwatersrand, Parktown, Johannesburg.

ORCID Number: 0000-0003-1875-8402

Corresponding author: Govindrau U Mohangi

Department of Oral Medicine \& Periodontology, School of Oral Health Sciences, Faculty of Health Science, University of the Witwatersrand, Parktown, Johannesburg.

Email: govindrau.mohangi@wits.ac.za

Author contributions:

1. Fatima Peer: Principal Investigator (requirement of MSc. Dent degree) - 50\%

2. Govindrau U Mohangi: Sole supervisor \& operator - $50 \%$

\author{
ACRONYMS \\ CAL: \\ CTG: \\ CAF: \\ EMD: \\ FGG: \\ GMTR: Gingival Marginal Tissue Recession \\ GT: \\ GTR: \\ KTW: \\ MGJ: \\ PD: \\ PES: \\ PRF: \\ RD: \\ RES: \\ Clinical Attachment Loss \\ Connective Tissue Grafts \\ Coronally Advanced Flaps \\ Enamel Matrix Derivative \\ Free Gingival Grafts \\ Gingival Thickness \\ Guided Tissue Regeneration \\ Keratinised Tissue Width \\ Mucogingival Junction \\ Periodontal Depth \\ Pink Esthetic Score \\ Platelet Rich Fibrin \\ Recession Depth \\ Root Esthetic Score \\ RW: \\ Recession Width
}

The aesthetic scores improved at four sites for both CTGs and PRF with only one site in each group scoring lower, whilst elsewhere scores did not change. Patients were satisfied with the aesthetic outcomes. Both CTGs and PRF membranes can be effective in treating gingival recession, improving clinical and aesthetic outcomes.

\section{INTRODUCTION}

Gingival marginal tissue recession (GMTR) is the exposure of a tooth's root surface as a result of apical migration of the soft tissue margin. ${ }^{1}$ It is a common dental complaint and has varied consequences; the most common being dentine hypersensitivity, enamel abrasion defects, root caries and compromised aesthetics in patients, particularly in those with high smile lines. ${ }^{2-5}$

Traditional management of these lesions includes monitoring and preventative supervision of aetiological factors or symptomatic treatment with dentine sealants or restorations. ${ }^{2,3}$ These conservative approaches neither restore lost gingival tissue nor aesthetics and in today's era of aesthetic perfection, the more discerning patient will be dissatisfied. Periodontal plastic surgery is the preferred treatment to address and enhance gingival architecture and to holistically improve aesthetics and function. 
Many surgical techniques have been used to treat GMTR. These include but are not limited to coronally advanced flaps (CAF), free gingival grafts (FGG), connective tissue grafts (CTG), guided tissue regeneration (GTR), allografts and xenografts. ${ }^{6,7}$ CTG in combination with a CAF is considered the gold standard to treat GMTR., ${ }^{5,7-14}$

This technique is well described, is predictable and has demonstrated significant improvements in root coverage, clinical attachment gain, keratinised tissue gain and with superior colour matching to adjacent tissues. ${ }^{4,11,15}$

Despite these advantages, CTG's pose some limitations. Donor tissue is customarily sourced from the palate which not only exposes the patient to a second surgical site, but postoperative healing may be retarded. ${ }^{4,16}$

A systematic review by Chambrone et al. reported multiple adverse reactions associated with a second surgical site: among others, postsurgical oedema, increased pain and necrosis of the palatal flap during the initial healing phase. $^{8}$ Anatomical considerations such as the position of the palatine neurovascular bundle may increase the risk of paraesthesia or permanent anaesthesia at the donor site.11,16 The palate is also limited in the amount of graft tissue it may donate, restricting the number of recessions that can be treated at one time..$^{11,16}$

This may necessitate repeated surgical interventions to correct multiple recession lesions. Furthermore, patients are usually anxious at the prospect of undergoing surgery in general, but more so when the palate is a surgical site. ${ }^{16}$

Eliminating the need for a second surgical site will reduce the morbidity of this procedure and patients may be more inclined to accept corrective surgery.

Alternatives to CTGs are barrier membranes, allografts, xenogeneic collagen membranes and enamel matrix derivative (EMD). The use of these membranes can be technique sensitive and complications have been docu-

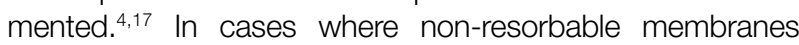
are used, a second surgery is required to remove the membrane and newly formed periodontal tissue may be damaged at that time. ${ }^{4}$ In some individuals, these materials are regarded as foreign bodies by recipient tissues and the natural healing process may be disrupted. ${ }^{18}$

Allografts and xenogeneic grafts remain associated with the risk of disease transmission, tissue rejection and may raise ethical concerns. ${ }^{4,16}$ Additionally, commercial membranes are costly and affordability may be an issue.

Lastly, some patients may not be willing to use xenogeneic membranes for personal or religious reasons as they are commonly derived from bovine or porcine sources. In sum, these alternative membranes are not an adequate substitute for CTGs. A more economical and potentially viable alternative could be platelet rich fibrin (PRF); a natural autologous material.

PRF is a second generation platelet concentrate, developed by Joseph Choukroun in the early 2000s. PRF can "activate and facilitate healing with the regenerative capacity of the host tissue, by providing a strong fibrin scaffold, major growth factors and by allowing space for tissue regeneration". 18

PRF is a healing biomaterial with a high-density fibrin network. ${ }^{19}$ This gel-like fibrin network is created by a slow and almost natural polymerisation process which allows for the slow release of the growth factors and cytokines within its fibrin clot which acts as a scaffold for cellular migration and proliferation. ${ }^{13}$

PRF is wholly autogenous as it is prepared from the patient's own blood. The preparation protocol is simple, efficient and relatively inexpensive. The resultant fibrin clot is enriched with platelets, B- and T-lymphocytes, monocytes, stem cells, neutrophilic granulocytes and growth factors. ${ }^{20}$ These physical properties can be harnessed to treat GMTR.

Both clinicians and patients have become more aesthetically astute, yet, soft tissue aesthetics is not routinely evaluated after gingival recession surgery. ${ }^{5,21}$ This study sought to evaluate aesthetics from the perspectives of patient and operator. However, aesthetic outcomes can be subjective. A numerical scoring systemcan therefore be useful to eliminate such bias and to provide reproducibility when judging aesthetic outcomes. ${ }^{21}$ The Pink Esthetic Score (PES) is such a system.

\section{AIMS AND OBJECTIVES}

This study set out to determine the clinical efficacies of PRF membranes and CTGs in treating GMTR. In addition, the authors wanted to evaluate the aesthetic outcomes using the PES and to determine patient satisfaction.

\section{DESIGN}

This six-month study was designed as a randomised split-mouth study and is presented as an extended case series.

\section{METHODS}

Patients were sourced from the Wits Oral Health Centre. Five patients, three males and two females aged between 29 and 69 years (mean age was 50.4) took part in this study.

Informed consent was obtained and all protocols for research patient management were followed. Ethical clearance was obtained from The Human Research Ethics Committee (Medical) at the University of the Witwatersrand who issued clearance certificate number M150506.

The inclusion criteria were: presence of at least two contralateral Miller's class | and/or class || recession lesions, patients had to be at least 18 years old, nonsmokers, in good systemic health with good periodontal health and able to maintain good oral hygiene.

The exclusion criteria were: recession lesions which were classified as Miller's class III or class IV recessions, 
multi-rooted teeth with furcation involvement, patients who were pregnant, had bleeding disorders or who had had previous periodontal surgery in an attempt to correct recessions in the areas of interest.

Aetiological factors were identified and addressed accordingly. Prophylaxis was carried out and patients were given oral hygiene instructions. The plaque control in these patients was $\leq 20 \% .^{22}$

The following clinical variables were recorded to the nearest millimetre $(\mathrm{mm})$ using a UNC 15 periodontal probe (Figure 1): periodontal depth (PD), recession depth (RD), recession width (RW), clinical attachment loss (CAL), keratinised tissue width (KTW) and gingival thickness (GT).
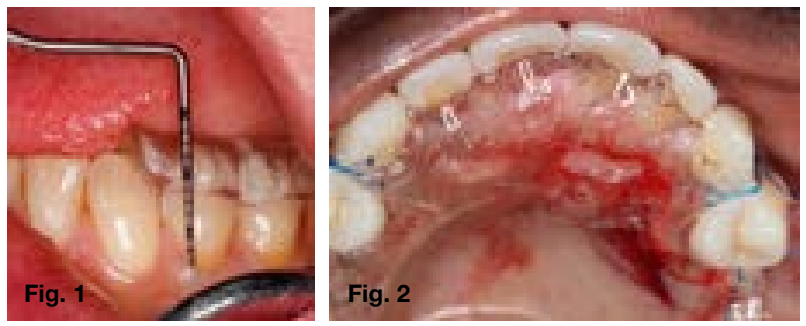

Figure 1. A UNC $15 \mathrm{Hu}$-Friedy periodontal probe used with acrylic measuring guide to record clinical parameters.

Figure 2. Palatal stent protecting donor site post-surgery.

All measurements except GT were recorded at weeks $0,8,12,16$ and 24. GT was measured using a rubber stopper at the end of an endodontic reamer and was recorded at baseline and at week 24 .

Under local anaesthesia, the reamer was pushed into the attached gingiva at the point corresponding to the vertical line of the mid-buccal groove of the measuring guide and the mid-point of the apico-coronal width of keratinised gingiva. Tactile sensation was used to determine the point at which the reamer made contact with bone. The rubber stopper demarcated the distance from the bone to the gingival surface and this distance was measured.

Acrylic measuring guides (see Figure 1) were used to ensure reproducibility of clinical measurements. The fitting surface of the measuring guides were designed to fit snugly over the coronal surface of each tooth. An acrylic bur was used to create narrow grooves on the buccal side. Each groove corresponded to each measuring point i.e. mesio-buccal, mid-buccal and distobuccal. The periodontal probe was placed in each of these grooves when recording measurements, thus ensuring reproducibility.
Before and after photographs were taken to compare aesthetic outcomes between the two groups. The Pink Esthetic Score was used for aesthetic evaluation..$^{23}$ At the end of the study period, patients were asked to complete a questionnaire designed to assess their satisfaction with treatment outcomes.

Each patient received both types of treatment, one on either side. Each site was randomly allocated to the control (CGT) or test(PRF) treatment using the RAND function in Microsoft Excel 2016.

\section{Surgical protocol}

All sites were treated with identical surgical procedures performed by the same operator. A modified CAF was created at recipient sites. Intrasulcular incisions were made around the necks of the teeth using 15c SwannMorton $₫$ surgical blades and Keydent $₫$ microsurgical discoid blades.

The incision was extended to the adjacent teeth on both sides. Hurzeler tunnelling instruments were used to extend the flap into the mucosal tissues. ${ }^{24}$ With this type of flap design, the interdental papillae remained connected and intact avoiding vertical relieving incisions thus eliminating potential scarring that could have compromised the aesthetic result.

For the control, the CTG was obtained from the palate. A palatal acrylic stent (Figure 2) was used in lieu of sutures and exerted pressure onto the donor site aiding haemostasis and pain management. The CTG was trimmed as necessary, transferred to the recipient site and carefully placed and threaded into the gingival tunnel which had been created.

The flap was secured with Seralon $\AA$ polyamide monofilament $4 / 0$ sutures using the double-crossed suture technique described by Zuhr and Hürzeler. ${ }^{25}$ Composite grooves (Figure 6) were created on the interproximal contact points providing a fulcrum to help advance the flap coronally and to provide maximum support for the graft.

At the test sites, Choukroun's A-PRF preparation protocol was used. ${ }^{26}$ Just prior to surgery, intravenous blood was collected from the antecubital fossa in $10 \mathrm{ml} \mathrm{A-PRF+}$ blood vials and immediately centrifuged using a PC-O2 centrifuge (Figure 3) at $1500 \mathrm{rpm}$ for eight minutes.

\begin{tabular}{|c|c|c|c|}
\hline Clinical Parameters & Mesio-buccal (MB) & Buccal (B) & Disto-buccal (DB) \\
\hline PD (periodontal probing depth)* & MB & B & DB \\
\hline RD (recession depth)* & MB & B & DB \\
\hline CAL (clinical attachment loss)* & MB & $B$ & DB \\
\hline RW (recession width) ${ }^{\star \star}$ & \multicolumn{3}{|c|}{$\begin{array}{l}\text { RW was measured using a UNC } 15 \text { probe at the widest horizontal distance between the mesial and the distal } \\
\text { margins of the recession defect. }\end{array}$} \\
\hline KTW (keratinised tissue width)** & \multicolumn{3}{|c|}{ KTW was measured using a UNC 15 probe along the vertical mid-buccal groove of the measuring guide. } \\
\hline GT (gingival thickness)** & \multicolumn{3}{|c|}{$\begin{array}{l}\text { GT was recorded using an endodontic reamer fitted at the tip with a rubber stopper, measuring at the point } \\
\text { where the vertical line of the mid-buccal groove of the measuring guide (see Figure 1) met the mid-point of } \\
\text { the width of keratinised gingiva. }\end{array}$} \\
\hline
\end{tabular}



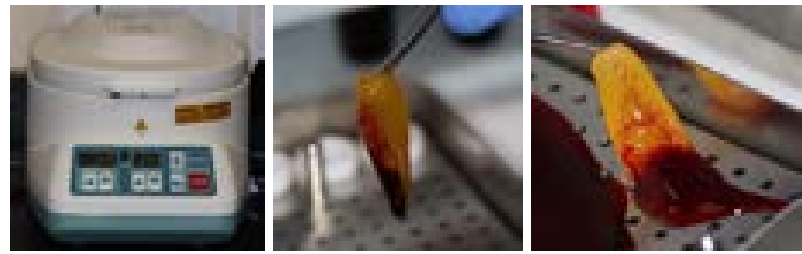

Figure 3. $\mathrm{PC}-\mathrm{O} 2$ centrifuge used to create PRF (A; Process, Nice France).

Figure 4. PRF clot with fibrin clot above, red thrombin base below and buffy coat between the two layers.

Figure 5. PRF clot placed in a Process PRF Box.

The centrifugation process separates the different blood constituents into three layers: an acellular supernatant plasma layer, a middle PRF clot layer and erythrocytes below. PRF is made up of a yellow fibrin clot with a red thrombus base and a whitish buffy coat between the two (see Figure 4).

The fibrin clot was removed and compressed into a membrane using a Process PRF Box (Figure 5). ${ }^{27}$ The compressed membrane was placed at the recipient site and sutured in the same way as the control site.

\section{Post-surgical protocol}

Patients were prescribed analgesics: paracetamol 500mg, 8-hourly for five days and ibuprofen 200mg, 8-hourly for three days, and a $0.2 \%$ aqueous chlorhexidine gluconate mouthwash for two minutes twice daily for two weeks.

Sutures were removed two weeks post-operatively. Patients were recalled at 8, 12, 16 and 24 weeks. On each occasion, the full set of measurements were recorded. At the end of the study period, photographs were taken and patients were requested to complete a questionnaire which required them to rate the following outcomes along a Likert scale: the position of the gingival margin, gingival colour, gingival shape and dentine hypersensitivty, rating from one (much worse than before) to five (noticeable improvement) (Table 2).

\section{Data analysis}

Descriptive statistics were presented for each variable in each patient at baseline and at 24 weeks. Each patient was a unit of analysis and outcomes were summarised and analysed independently.

In patients with multiple paired sites (patients $\mathrm{E}$ and F), the mean of each variable was used for statistical analysis and t-tests were used to compare baseline and 24 week values. In addition, the percentage root coverage, as well as root coverage (yes/no) was derived. Data analysis was carried out with Microsoft Excel 2016 statistical analysis software.

For each patient with single paired sites, data was ordinal and was summarised and analysed individually. In those patients with multiple paired sites, data were summarised as a mode.

\section{RESULTS AND DISCUSSION}

The sample population consisted of five patients, three males and two females aged between 29 and 69 years (mean age was 50.4). Patients were enrolled and surgical treatments completed between January and June 2016. Patients were seen for a total of five recall appointments over six months and the observational period concluded in December 2016.

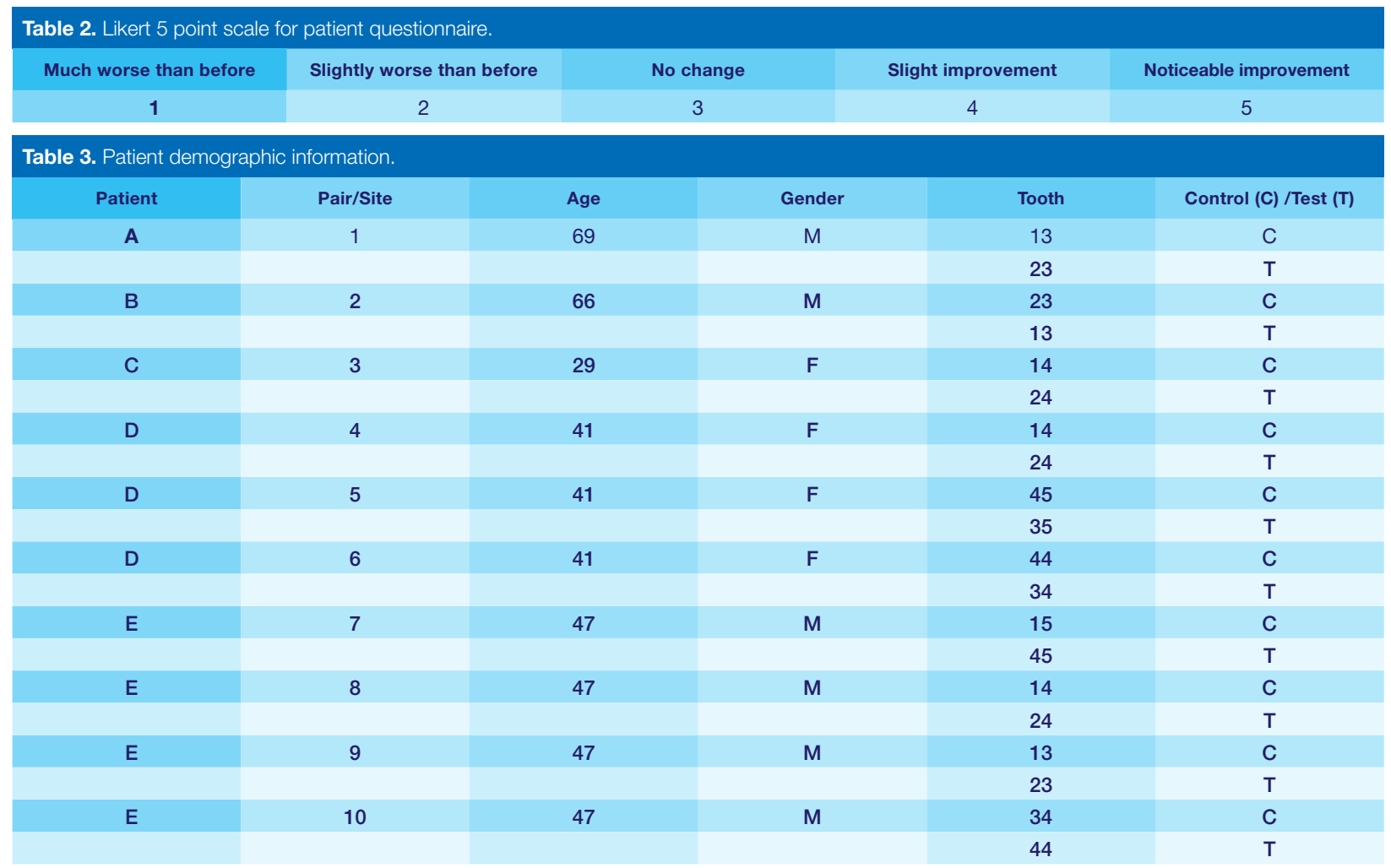


Between the five patients, there was a total of twenty sites (i.e. ten paired sites). Patients A, B and C presented with one pair of recession sites each, patient $D$ presented with three paired sites and patient $E$ with four paired sites.

The results for each patient are presented in the Tables below. Tables $4 \mathrm{a}$ and $4 \mathrm{~b}$ summarise baseline and 24 week measurements of all clinical variables and the PES. Table 4c summarises the scores from the questionnaire.

The purpose of this study was to evaluate the clinical and aesthetic results achieved with the use of CTGs and of PRF. Each patient was a unit of analysis and independently analysed. ${ }^{29}$ Single paired sites are presented as Pairs 1, 2 and 3, whilst pairs 4, 5 and 6 were from one patient and pairs 7, 8, 9, and 10 were from another patient.

\section{Clinical outcomes}

The primary variables analysed to determine clinical improvements in root coverage were RD and RW. Keratinised tissue changes (KTW and GT) were secondary outcomes. Although there were improvements at both CTG and PRF sites, there were a greater number

\begin{tabular}{|c|c|c|c|c|c|c|c|c|c|c|c|c|c|c|c|c|}
\hline & \multicolumn{4}{|c|}{ PD } & \multicolumn{4}{|c|}{ RD } & \multicolumn{4}{|c|}{ RW } & \multicolumn{4}{|c|}{ CAL } \\
\hline & \multicolumn{2}{|c|}{ Control } & \multicolumn{2}{|c|}{ Test } & \multicolumn{2}{|c|}{ Control } & \multicolumn{2}{|c|}{ Test } & \multicolumn{2}{|c|}{ Control } & \multicolumn{2}{|c|}{ Test } & \multicolumn{2}{|c|}{ Control } & \multicolumn{2}{|c|}{ Test } \\
\hline & $\begin{array}{c}\text { Week } \\
0\end{array}$ & $\begin{array}{c}\text { Week } \\
24\end{array}$ & $\begin{array}{c}\text { Week } \\
0\end{array}$ & $\begin{array}{c}\text { Week } \\
24\end{array}$ & $\begin{array}{c}\text { Week } \\
0\end{array}$ & $\begin{array}{c}\text { Week } \\
24\end{array}$ & $\begin{array}{c}\text { Week } \\
0\end{array}$ & $\begin{array}{c}\text { Week } \\
24\end{array}$ & $\begin{array}{c}\text { Week } \\
0\end{array}$ & $\begin{array}{c}\text { Week } \\
24\end{array}$ & $\begin{array}{c}\text { Week } \\
0\end{array}$ & $\begin{array}{c}\text { Week } \\
24\end{array}$ & $\begin{array}{c}\text { Week } \\
0\end{array}$ & $\begin{array}{c}\text { Week } \\
24\end{array}$ & $\begin{array}{c}\text { Week } \\
0\end{array}$ & $\begin{array}{c}\text { Week } \\
24\end{array}$ \\
\hline Pair 1 & 2 & 2 & 2 & 2 & 3,67 & 2,33 & 2,67 & 2,33 & 7 & 6 & 7 & 6 & 5,67 & 4,33 & 4,67 & 4,33 \\
\hline Pair 2 & 2 & 2 & 3,33 & 3 & 2,67 & 1,33 & 3 & 1,33 & 5 & 4 & 5 & 4 & 4,67 & 3,33 & 6,33 & 4,33 \\
\hline Pair 3 & 2 & 2 & 2 & 2,33 & 0,67 & 0,33 & 0,67 & 0,67 & 3 & 0 & 4 & 3 & 2,67 & 2,33 & 2,67 & 3 \\
\hline Pair 4 & 2 & 2 & 1,67 & 2 & 1,33 & 1,33 & 1 & 0,67 & 4 & 4 & 3 & 3 & 3,33 & 3,33 & 2,67 & 2,67 \\
\hline Pair 5 & 2 & 2,33 & 2,33 & 2 & 1,33 & 2,33 & 1,67 & 1,33 & 3 & 3 & 4 & 4 & 3,33 & 4,67 & 3,67 & 3,33 \\
\hline Pair 6 & 2,33 & 1,67 & 2 & 2 & 1,33 & 1 & 1,33 & 1,33 & 3 & 3 & 4 & 3 & 3,67 & 2,67 & 3,33 & 3,33 \\
\hline Pair 7 & 2 & 2 & 1,67 & 2,33 & 1,67 & 1,33 & 1,67 & 1 & 5 & 5 & 4 & 5 & 3,67 & 3,33 & 3,33 & 3,33 \\
\hline Pair 8 & 1,67 & 2 & 1,67 & 2 & 2,33 & 2,33 & 1,33 & 1,33 & 5 & 5 & 5 & 5 & 4 & 4,33 & 3 & 3,33 \\
\hline Pair 9 & 2 & 2,67 & 2 & 4,67 & 0,67 & 1,33 & 1,67 & 2 & 4 & 5 & 6 & 6 & 2,67 & 4 & 3,67 & 6,67 \\
\hline Pair 10 & 2 & 2,67 & 2 & 2,33 & 2,67 & 2 & 1 & 1,33 & 5 & 5 & 4 & 4 & 4,67 & 4,67 & 3 & 3,67 \\
\hline
\end{tabular}

\begin{tabular}{|c|c|c|c|c|c|c|c|c|c|c|c|c|}
\hline & \multicolumn{4}{|c|}{ KTW } & \multicolumn{4}{|c|}{ GT } & \multicolumn{4}{|c|}{ PES } \\
\hline & \multicolumn{2}{|c|}{ Control } & \multicolumn{2}{|c|}{ Test } & \multicolumn{2}{|c|}{ Control } & \multicolumn{2}{|c|}{ Test } & \multicolumn{2}{|c|}{ Control } & \multicolumn{2}{|c|}{ Test } \\
\hline & $\begin{array}{c}\text { Week } \\
0\end{array}$ & $\begin{array}{c}\text { Week } \\
24\end{array}$ & $\begin{array}{c}\text { Week } \\
0\end{array}$ & $\begin{array}{c}\text { Week } \\
24\end{array}$ & $\begin{array}{c}\text { Week } \\
0\end{array}$ & $\begin{array}{c}\text { Week } \\
24\end{array}$ & $\begin{array}{c}\text { Week } \\
0\end{array}$ & $\begin{array}{c}\text { Week } \\
24\end{array}$ & $\begin{array}{c}\text { Week } \\
0\end{array}$ & $\begin{array}{c}\text { Week } \\
24\end{array}$ & $\begin{array}{c}\text { Week } \\
0\end{array}$ & $\begin{array}{c}\text { Week } \\
24\end{array}$ \\
\hline Pair 1 & 2 & 2 & 2 & 2 & 1 & 1.5 & 0.5 & 1 & 11 & 12 & 10 & 12 \\
\hline Pair 2 & 3 & 2 & 4 & 5 & 0.5 & 1 & 1.5 & 1 & 8 & 8 & 11 & 12 \\
\hline Pair 3 & 4 & 6 & 4 & 6 & 1 & 1.5 & 1 & 1 & 14 & 13 & 14 & 14 \\
\hline Pair 4 & 4 & 1 & 3 & 5 & 1 & 1 & 1 & 1 & 11 & 12 & 14 & 14 \\
\hline Pair 5 & 2 & 3 & 2 & 2 & 1.5 & 1.5 & 1 & 1 & 14 & 14 & 14 & 14 \\
\hline Pair 6 & 1 & 1 & 2 & 2 & 0.5 & 0.5 & 1 & 1 & 13 & 13 & 14 & 14 \\
\hline Pair 7 & 4 & 4 & 2 & 2 & 1 & 2 & 0.5 & 1 & 8 & 11 & 11 & 11 \\
\hline Pair 8 & 3 & 4 & 6 & 5 & 1.5 & 2 & 1.5 & 2 & 10 & 10 & 9 & 10 \\
\hline Pair 9 & 4 & 4 & 4 & 3 & 1 & 1.5 & 1 & 1 & 10 & 10 & 11 & 10 \\
\hline Pair 10 & 3 & 1 & 3 & 3 & 1 & 1 & 1 & 1 & 11 & 13 & 12 & 13 \\
\hline
\end{tabular}

\begin{tabular}{|c|c|c|c|c|c|c|c|c|}
\hline & \multicolumn{2}{|c|}{ Margin Gingival Level } & \multicolumn{2}{|c|}{ Gingival Colour } & \multicolumn{2}{|c|}{ Gingival Shape } & \multicolumn{2}{|c|}{$\begin{array}{c}\text { Dentine } \\
\text { Hypersensitivity }\end{array}$} \\
\hline & Control & Test & Control & Test & Control & Test & Control & Test \\
\hline Pair 1 & 3 & 3 & 3 & 3 & 3 & 3 & 4 & 4 \\
\hline Pair 2 & 4 & 4 & 5 & 5 & 3 & 3 & 3 & 3 \\
\hline Pair 3 & 3 & 3 & 3 & 3 & 3 & 3 & 5 & 5 \\
\hline Pair 4 & 2 & 4 & 3 & 3 & 3 & 3 & 2 & 5 \\
\hline Pair 5 & 2 & 4 & 3 & 3 & 3 & 3 & 2 & 5 \\
\hline Pair 6 & 2 & 4 & 3 & 3 & 3 & 3 & 2 & 5 \\
\hline Pair 7 & 5 & 5 & 5 & 5 & 5 & 5 & 5 & 5 \\
\hline Pair 8 & 5 & 5 & 5 & 5 & 5 & 5 & 5 & 5 \\
\hline Pair 9 & 5 & 5 & 5 & 5 & 5 & 5 & 5 & 5 \\
\hline Pair 10 & 5 & 5 & 5 & 5 & 5 & 5 & 5 & 5 \\
\hline
\end{tabular}


of CTG sites which demonstrated improvements in measurements of recession. Of the total sites treated, six of the ten control sites and five of the ten test sites demonstrated root coverage.

In the single paired sites 1 and 3 , the control sites showed greater improvements in RD measurements than did the test sites while test site 2 showed a greater improvement than its corresponding control site (Table 4a).

In patients with single paired sites, RW improved at all sites in both groups. RW changes between the control and test sites for pair 2 were the same. However, control site 3 showed a 100\% improvement while test site 3 showed a less favourable $25 \%$ improvement (Table 4a).

Overall in the single paired sites, CTG recorded the better performance. At the two week recall appointment, patient B reported that some tissue had been lost from the CTG (control) site. Poorer results at this site (2) could be due to this loss, leading to a compromised outcome at this particular CTG site.

CAL decreased at all single paired sites (Table 4a). In patient 1 , the control site performed better with a $24 \%$ improvement whereas the test site demonstrated a $7 \%$ improvement.

In patients 2 and 3, the control and test sites showed similar decreases in CAL (patient 2: $29 \%$ at the control and $32 \%$ at the test site; patient 3: $12 \%$ at the control and $13 \%$ at the test site). This demonstrates that both CTGs and PRF have similar potential to improve clinical attachment levels.

In patients $D$ and $E$, descriptive statistics and t-tests revealed similar improvements for both control and test groups. In patient D, the individual test sites displayed slightly better results in RD and CAL than did the control sites (the test sample variance results were slightly lower if not similar and the mean was lower than the hypothesised mean).

Descriptive statistics and t-tests revealed that while the improvement for both control and test was the same, i.e. the high $\mathrm{p}$-value indicates that the null hypothesis is supported (Tables $5 a$ and $5 b$ ), skewness and kurtosis could only be calculated for the RD and $\mathrm{CAL}$ distributions. However, in patient $\mathrm{E}$ these distributions differed in that the control favoured negatively scored distributions while the test positively scored. This supports that the test sample variance results were slightly lower if not similar and the mean is lower than the hypothesised mean. In patient E, t-Tests cannot be reliably used for the RW, KTW and GT since Microsoft Excel returned undefined (divide by zero) scores for the distributions. These are noted as " $U$ " in the table. In patient $F$, the RD and CAL distributions exhibited similar scores. This supports the use of the findings. However, in patient F, t-Tests cannot be reliably used for the RW, KTW and GT the score for the other three measures were fairly extreme.

These results in patients $D$ and $E$ are mirrored in a similarly designed study by Jankovic et al. where CTG performance was compared with that of $\mathrm{PRF}^{30}$ It was found that RD improved in both groups with no statistical difference between groups. ${ }^{30} \mathrm{RW}$ measurements in these patients remained unchanged at most sites (11 of the 14 sites).

Of the three sites that demonstrated a change in RW, only one site improved (test site 6 improved by $1 \mathrm{~mm}$ ). The other two sites worsened by $1 \mathrm{~mm}$ each (test site 7 and control site 9). These results demonstrate that both CTGs and PRF have the potential to improve recession lesions (Table 4a).

There were improvements in GT at many sites, $60 \%$ of CTG sites demonstrating an increase in GT while only $30 \%$ of the PRF sites increased in GT (Table $4 \mathrm{~b}$ ).

CTGs demonstrated an increased tendency over PRF to improve GT. Few studies report on changes in GT, only two being found. Both were over a six month observational period and GT was recorded at baseline and six months. ${ }^{10,11}$

One of the studies was conducted by Eren and Atilla, evaluating and comparing CTGs and PRF in combination with a CAF. The authors found similar statistically significant improvements in GT measurements in both groups. ${ }^{11}$ The present study, on the other hand, showed a greater increase at the CTG sites. A second study; by Aroca et al. tested a CAF alone with a CAF combined with PRF and found statistically significant improvements in GT in the PRF group. ${ }^{10}$

These results demonstrate that a CAF in combination with PRF can be more beneficial than using a CAF alone in treating gingival recession. The present study has

\begin{tabular}{|c|c|c|c|c|c|c|c|c|c|c|c|}
\hline \multirow{4}{*}{ Patient $\mathrm{E}$} & \multirow{3}{*}{$\begin{array}{c}\mathrm{P}(\mathrm{T}<=\mathrm{t}) \text { two-tail } \\
\text { Kurtosis }\end{array}$} & \multicolumn{2}{|c|}{ RD } & \multicolumn{2}{|c|}{ CAL } & \multicolumn{2}{|c|}{ RW } & \multicolumn{2}{|c|}{ KTW } & \multicolumn{2}{|c|}{ GT } \\
\hline & & \multicolumn{2}{|c|}{0.35} & \multicolumn{2}{|c|}{0.71} & \multicolumn{2}{|c|}{0.42} & \multicolumn{2}{|c|}{0.55} & \multicolumn{2}{|c|}{ N/A } \\
\hline & & -0.01 & 0.73 & -1.25 & 1.13 & U & U & U & $u$ & $u$ & $u$ \\
\hline & Skewness & -0.50 & 1.62 & -0.68 & 0.02 & $u$ & 1.73 & 1.29 & -1.73 & u & u \\
\hline & & \multicolumn{2}{|c|}{ RD } & \multicolumn{2}{|c|}{ CAL } & \multicolumn{2}{|c|}{ RW } & \multicolumn{2}{|c|}{ KTW } & \multicolumn{2}{|c|}{ GT } \\
\hline \multirow{3}{*}{ Patient $\mathrm{F}$} & $\mathrm{P}(\mathrm{T}<=\mathrm{t})$ two-tail & \multicolumn{2}{|c|}{0,79} & \multicolumn{2}{|c|}{0,12} & \multicolumn{2}{|c|}{1,00} & \multicolumn{2}{|c|}{0,79} & \multicolumn{2}{|c|}{0,18} \\
\hline & Kurtosis & $-0,19$ & $-0,86$ & $-0,25$ & $-1,28$ & 4,00 & 4,00 & 2,23 & $-6,00$ & 1,50 & $-6,00$ \\
\hline & Skewness & $-0,09$ & 0,00 & $-0,14$ & $-0,46$ & $-2,00$ & $-2,00$ & 1,13 & 0,00 & 0,00 & 0,00 \\
\hline
\end{tabular}


demonstrated that CTGs provide greater improvements in GT over PRF. The increase in GT at the CTG sites can be explained by the influence of the type of connective tissue involved. Subepithelial connective tissue from keratinised mucosa contains the biological signals that induce the overlying epithelium to differentiate into the keratinised form. ${ }^{11,31-33}$

The increase in GT in the PRF group may be explained by the influences of the growth factors trapped within the PRF membrane. ${ }^{11}$ These growth factors positively influence proliferation and differentiation of the gingival and periodontal ligament fibroblasts and epithelial cells, encouraging angiogenesis. ${ }^{30}$

The dense 3-dimensional fibrin structure of PRF may also function in a similar fashion to an extracellular matrix by providing stability to the wound and acting as a scaffold for cellular interactions, thereby increasing the thickness of the overlying epithelium. ${ }^{19}$

An increase in GT contributes to complete root coverage, long-term periodontal stability and helps prevent further gingival recession over time. ${ }^{29,30}$ Therefore, increases in GT is a desired outcome of any surgical treatment. Although both CTGs and PRF demonstrated the potential to positively influence GT, CTGs performed better at this than did PRF.

The KTW results showed improvements in only six of the twenty sites (control sites 3, 5 and 8 and test sites 2, 3 and 4). There were decreases in KTW at three control sites (2, 4 and 10) and at two test sites (8 and 9) while at the remaining sites the levels remained unchanged. In their CTG and PRF study, Jankovic et al. observed a different outcome over six months with a statistically significant gain in KTW in both groups. ${ }^{29}$

Overall, both CTGs and PRF can improve clinical outcomes in treating gingival recessions but CTGs demonstrated improved clinical outcomes at a greater number of sites. These findings support the view of many authors that CTGs together with a CAF produce the best results in treating recessions.

\section{Aesthetic outcomes}

According to Chambrone et al. improved gingival aesthetics is considered the primary goal of root coverage procedures. ${ }^{37}$ Zucchelli et al. states that root coverage success should be determined not only by reductions in recession measurements but also by soft tissue coverage, the thickness and colour of which should be indistinguishable from those of adjacent soft tissue. ${ }^{38}$ Photographs were taken and the PES was used as an objective aesthetic scoring system. The PES uses seven variables on a scale 0-1-2 for a total score of 14. Aesthetic outcomes were determined on how close/short of this total were the recorded values.

The application of both CTGs and PRF can result in improved aesthetic outcomes. The aesthetic results in both groups were similar and no patient was dissatisfied. Across the groups, there were eight sites with an increased PES, ten sites with no change and two sites that decreased in their score. The increases in the PES were distributed equally between the control and test sites i.e. control sites 1, 4, 7 and 10 and test sites, 1, 2, 8 and 10 .

The decreases in the PES were at control site 3 and test site 9. At both sites, there was a change from a perfect score of two ("natural") on soft tissue contour to a "fairly natural" score of one. This change in tissue contour may be the result of the surgical incisions into the sulcus and not necessarily as a result of the graft or use of the PRF membrane. The remaining sites displayed an improvement in the PES or an unchanged aesthetic score i.e. the aesthetic score did not worsen. Therefore, both CTGs and PRF have the potential to improve gingival aesthetics or at the very least, to maintain aesthetics.

There are limited studies that have systematically evaluated aesthetic outcomes using various types of visual scoring systems. Some studies simply comment on aesthetic outcomes using either general terms such as "aesthetically pleasing" or "good aesthetic results", or a by using a scale similar to "good", "regular" or "poor". 39,40

In a study by Rosetti et al. aesthetic results were evaluated on a scale of "good, regular and poor". ${ }^{41}$ The authors recognised that this type of scoring system is dependent on a subjective clinical impression. ${ }^{41}$ Another study by Bouchard et al. used a scoring system of "good, moderate and poor". ${ }^{42}$ They too acknowledged that this type of evaluation was subjective and tried to eliminate this bias by using independent examiners to evaluate the aesthetic outcomes. ${ }^{42}$

These methods of scoring aesthetics are not ideal as they are not only subjective but also are not reproducible. In contrast, the present study relied on a more objective means to evaluate aesthetics. The PES is a reproducible, reliable and predictable scoring system which evalu-

\begin{tabular}{|c|c|c|c|c|}
\hline Variables & Details & 0 & 1 & 2 \\
\hline Mesial papilla & Shape vs. reference tooth & Absent & Incomplete & Complete \\
\hline Distal papilla & Shape vs. reference tooth & Absent & Incomplete & Complete \\
\hline Marginal Tissue Level & Level vs. reference tooth & $\begin{array}{c}\text { Major discrepancy } \\
>2 \mathrm{~mm}\end{array}$ & $\begin{array}{c}\text { Minor discrepancy } \\
1-2 m m\end{array}$ & $\begin{array}{c}\text { No discrepancy } \\
<1 \mathrm{~mm}\end{array}$ \\
\hline Soft Tissue Contour & Natural matching reference tooth & Unnatural & Fairly natural & Natural \\
\hline Alveolar Process & Alveolar process deficiency & Obvious & Slight & None \\
\hline Soft Tissue Colour & Colour vs reference tooth & Obvious difference & Moderate difference & No difference \\
\hline Soft Tissue Texture & Texture vs reference tooth & Obvious difference & Moderate difference & No difference \\
\hline
\end{tabular}


ates seven specific characteristics of gingival tissue. ${ }^{23}$ Studies which evaluated aesthetic results prior to the development of an aesthetic scoring systems cannot be compared with the results of this study.

\section{Patient-based outcomes}

According to Bouchard et al. the success of root coverage procedures should be determined by the patient and not the clinician. ${ }^{40}$ The ultimate goal of any treatment is patient satisfaction.

To this aim, patients were given a questionnaire to score treatment outcomes on a Likert type scale. The questionnaire was given to patients at the end of the study period. Patients were asked to score four features of each site: marginal gingival level, gingival colour, gingival shape and dentine hyper-sensitivity.

The scoring system was a five point scale: 1 - much worse than before, 2 - slightly worse than before, 3 - no change, 4 - slight improvement and 5 - noticeable improvement.

All patients appeared satisfied with the aesthetic results. According to the patient questionnaire, most sites across both groups either improved or remained unchanged. Patient D was the exception.

She scored the gingival level at all three control sites as "slightly worse than before" and the corresponding test sites as "slightly improved". Her perception is mirrored in the clinical results where the statistical analysis showed that the control group worsened by $16 \%$ and the test group improved by $16.54 \%$. With regards to aesthetic outcomes, this patient scored gingival colour and shape as unchanged at all sites.

Again, this is reflected in the PES. The PES for these sites showed either an improvement (control site 4) or it remained unchanged at a perfect score of 14 . Analysis of patient D's questionnaire supports the concept that patients can constructively contribute to determining the success or failure of clinical outcomes.

On the other hand, patient E scored all control and test sites as 5 -"noticeable improvement". The clinical assessment of the results differed in that some of these sites worsened (i.e. control site 9 and test sites 9 and 10), three sites improved (control sites 7 and 10 and test site 7) and two sites remained unchanged (both control and test sites 8) over the study period.

These incongruities between clinical results and the patient's perceptions show a tendency of bias on the part of the patient. He may be simply wanting to favour a good result for the investigators. This shows that a patient's perceptions can be skewed with respect to the reality of outcomes.

Similarly, patient B scored the gingival margin as "slightly improved" and gingival colour as "noticeable improvement" at the CTG site even though there was no change in the PES. Clinicians may not deem this site an aesthetic success but the patient seemed satisfied with the overall result. Again, the patient may be eager to favour good study results. This concept is known as participant bias and is well documented in psychological studies.

Participant bias occurs when participants want to make a useful contribution to the study and so will provide what they think are the "correct" answers to provide the investigators with what they want. ${ }^{43}$

Despite this limitation, patients overall appeared satisfied with the aesthetic outcomes. There were no scores in the PRF group that worsened. Very few studies have considered aesthetic outcomes from a patient-based approach. In their systematic review of root coverage procedures, Chambrone et al. found only three randomised clinical trials that evaluated aesthetic outcomes according to patient opinions. ${ }^{37}$ As with the present study, Chambrone et al. found that when patients were asked to evaluate aesthetic results, most were satisfied with the outcome. ${ }^{37}$

Rotundo et al. set out to determine aesthetic perceptions after root coverage and interestingly found that clinicians expect patients to be fully satisfied with aesthetic results only when complete root coverage is achieved. ${ }^{44}$ However, the present study found that patients can be satisfied with the aesthetic result even in the absence of complete root coverage.

\section{Outcomes}

In this study, procedures using both connective tissue grafts (CTGs) and platelet rich fibrin (PRF) demonstrated clinical and aesthetic improvements in the management of gingival recession. The results obtained for recession depth (RD), clinical attachment loss (CAL) and gingival thickness (GT) were better in the CTG group whereas PRF demonstrated better results for recession width $(\mathrm{RW})$ and keratinised tissue width (KTW).

This study appears to be the first to have relied on an objective and a reproducible aesthetic scoring system, the Pink Esthetic System (PES). The aesthetic outcomes were judged to be the same for both groups. The protocol ensured the best possible results by not only using a tunnel flap, previously shown to enhance aesthetic results, but also with a microsurgical approach to minimise soft tissue trauma during surgery.

This study also considered patient based outcomes. The results from the questionnaire demonstrated that in the opinion of the patients, PRF performed better than CTG.

The results of this study indicate that both CTGs and PRF membranes can be effective in treating gingival recession and both treatments can improve clinical and aesthetic outcomes.

\section{Limitations}

This study used photographs and the PES to evaluate aesthetics. The PES does not accommodate the mucogingival junction (MGJ) in its analysis. In com- 


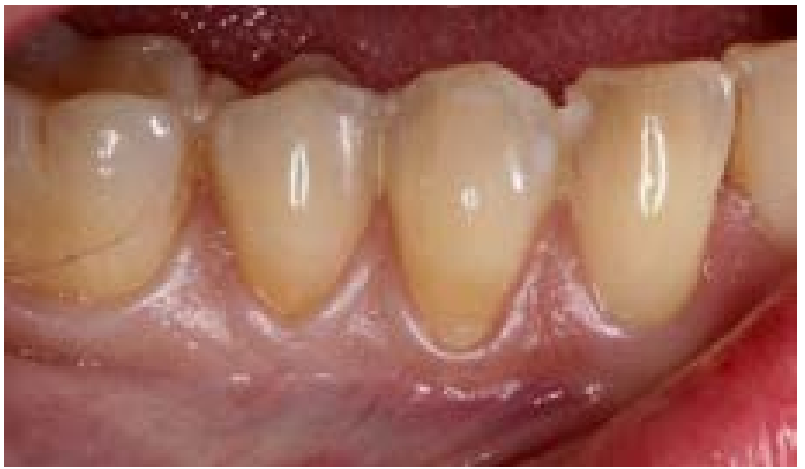

Figure 6. CTG sites on 44 and 45 at baseline.

Note: the interproximal composite rests created to support the sutures.

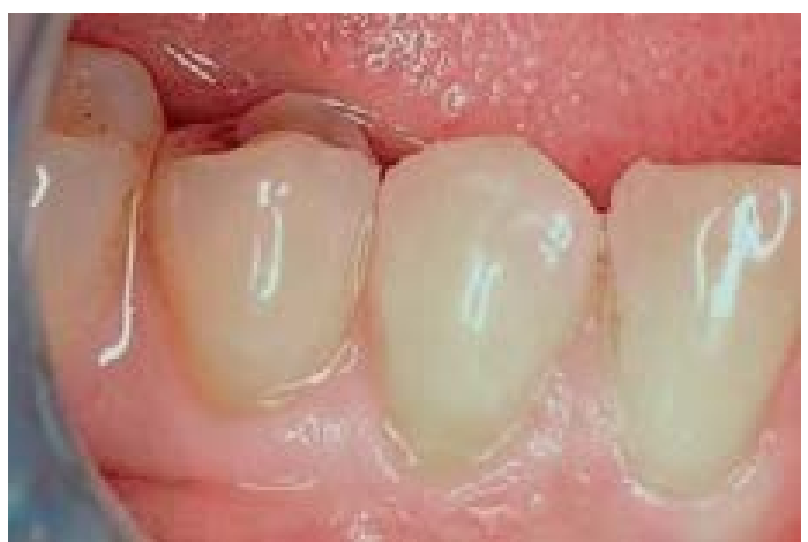

Figure 7. CTG sites on 44 and 45 at 6 months.

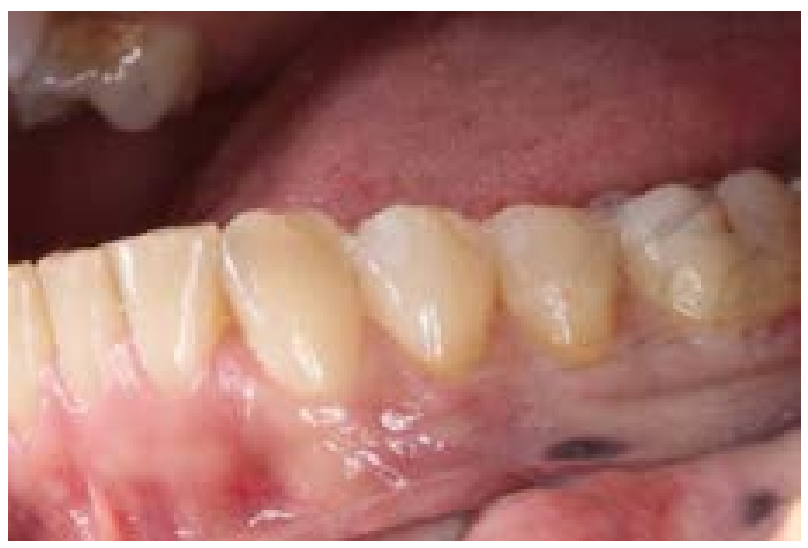

Figure 8. PRF treated sites on 34 and 35 at baseline.

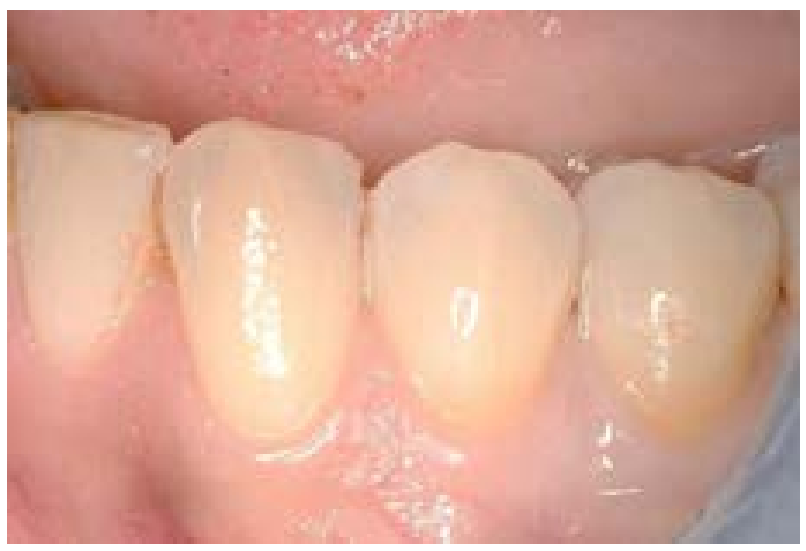

Figure 9. PRF sites on 34 and 35 at 6 months. fically designed to evaluate the aesthetic outcomes of root coverage procedures and as such uses clinical assessment of MGJ alignment as one of its variables. ${ }^{21}$

It can be challenging to identify the MGJ on photographs. By evaluating aesthetics clinically using the RES, the aesthetic score may be more representative of the outcomes of root coverage treatments.

Another limitation of this study was the method used to determine patient satisfaction. In the nature of our work, we develop relationships with our patients. This is expected as we build a rapport with our patients and develop trust over time. Despite this being a clinical study, the relationships still establish and anonymity cannot be secured in the clinical setting. Patients may therefore feel "obligated" to provide what they consider as favourable outcomes. Ensuring complete anonymity with regards to every aspect of the questionnaire may overcome this bias.

In future studies, an additional questionnaire before treatment to assess initial patient assessments of their aesthetic status may be helpful to enable comparison with their perceptions of treatment outcomes.

\section{Acknowledgements}

The principal author wishes to acknowledge Taariq Surtee and the invaluable help he provided at every step of this journey not only with data analysis and interpretation but also his support and encouragement throughout this study.

Thank you to Dr Rhoodie Garrana for his assistance with phlebotomies and photography expertise.

Thank you to Hartshorne Dental for their generosity in contributing to the surgical materials needed for this project.

\section{Conflict of interest}

The authors report no conflict of interest related to this study.

\section{References}

1. Maynard Jr JG, Wilson RDK. Physiologic dimensions of the periodontium significant to the restorative dentist. J Periodontol. 1979; 50(4): 170-4.

2. Patel $M$, Nixon $P$, Chan $M-Y$. Gingival recession: Part 1. Aetiology and non-surgical management. Br Dent J. 2011; 211(6): 251-4.

3. Tugnait A, Clerehugh V. Gingival recession-its significance and management. J Dent. 2001; 29(6): 381-94.

4. Zucchelli G, Mounssif I. Periodontal plastic surgery. Periodontol 2000. 2015; 68(1): 333-68.

5. Roccuzzo M, Bunino M, Needleman I, Sanz M. Periodontal plastic surgery for treatment of localized gingival recessions: a systematic review. J Clin Periodontol. 2002; 29 (suppl 3): 178-94.

6. Patel M, Nixon P, Chan M-Y. Gingival recession: Part 2. Surgical management using pedicle grafts. Br Dent J. 2011; 211(7): 315-9.

7. Patel M, Nixon P, Chan M-Y. Gingival recession: part 3. Surgical management using free grafts and guided tissue regeneration. Br Dent J. 2011; 211(8): 353-8. 
8. Chambrone L, Chambrone D, Pustiglioni FE, Chambrone LA, Lima LA. Can subepithelial connective tissue grafts be considered the gold standard procedure in the treatment of Miller Class I and II recession-type defects? J Dent. 2008; 36(9): 659-71.

9. Jankovic S, Aleksic Z, Milinkovic I, Dimitrijevic B. The coronally advanced flap in combination with platelet-rich fibrin (PRF) and enamel matrix derivative in the treatment of gingival recession: a comparative study. Eur J Esthet Dent. 2010; 5(3): 260-73.

10. Aroca S, Keglevich T, Barbieri B, Gera I, Etienne D. Clinical evaluation of a modified coronally advanced flap alone or in combination with a platelet-rich fibrin membrane for the treatment of adjacent multiple gingival recessions: a 6-month study. J Periodontol. 2009; 80(2): 244-52.

11. Eren G, Atilla G. Platelet-rich fibrin in the treatment of localized gingival recessions: a split-mouth randomized clinical trial. Clin Oral Investig. 2014; 18(8): 1941-8.

12. Pini-Prato G, Nieri M, Pagliaro U, Giorgi TS, La Marca M, Franceschi $D$, et al. Surgical treatment of single gingival recessions: Clinical guidelines. Eur J Oral Implantol. 2014; 7(1): 9-43.

13. Keceli HG, Kamak G, Erdemir EO, Evginer MS, Dolgun A. The adjunctive effect of platelet-rich fibrin to connective tissue graft in the treatment of buccal recession defects: Results of a randomized, parallel-group controlled trial. Periodontol. 2015; 86(11): 1221-30.

14. Chambrone L, Faggion Jr CM, Pannuti CM, Chambrone LA. Evidence-based periodontal plastic surgery: an assessment of quality of systematic reviews in the treatment of recession-type defects. J Clin Periodontol. 2010; 37(12): 1110-8.

15. Gholami GA, Saberi A, Kadkhodazadeh M, Amid R, Karami D. Comparison of the clinical outcomes of connective tissue and acellular dermal matrix in combination with double papillary flap for root coverage: A 6-month trial. Dent Res $J$ (Isfahan). 2013; 10(4): 506-13.

16. Ramachandra SS, Rana R, Reetika S, Jithendra K. Options to avoid the second surgical site: a review of literature. Cell Tissue Bank. 2014; 15(3): 297-305.

17. Abhishek Vivek Haridas DPC, Deepika P.C. and Y.V. Nagarjuna Reddy. Complications of GTR. Int J Appl Basic Med Res (Internet). 2014 18/04/2018 [cited 2018 18/04/2018]; 4(2): 149-54. Available from: http://www.cibtech.org/jms.htm.

18. Hartshorne J, Gluckman H. A comprehensive clinical review of Platelet Rich Fibrin (PRF) and its role in promoting tissue healing and regeneration in dentistry. Part II: Preparation, optimization, handling and application, benefits and limitations of PRF. Int Dent Afr. 2016; 6(5): 34-50.

19. Choukroun J, Diss A, Simonpieri A, Girard M-O, Schoeffler C, Dohan SL, et al. Platelet-rich fibrin (PRF): a second-generation platelet concentrate. Part IV: Clinical effects on tissue healing. Oral Surg Oral Med Oral Pathol Oral Radiol Endod. 2006; 101(3): e56-60.

20. Hartshorne J, Gluckman H. A comprehensive clinical review of Platelet Rich Fibrin (PRF) and its role in promoting tissue healing and regeneration in dentistry. Part I: Definition, development, biological characteristics and function. Int Dent Afr. 2016; 6(5): 14-24.

21. Cairo F, Rotundo R, Miller Jr PD, Pini Prato GP. Root coverage esthetic score: a system to evaluate the esthetic outcome of the treatment of gingival recession through evaluation of clinical cases. J Periodontol. 2009; 80(4): 705-10.

22. Montevecchi M, Moreschi A, Gatto MR, Checchi L, Checchi V. Evaluation of clinical effectiveness and subjective satisfaction of a new toothbrush for postsurgical hygiene care: a randomized split-mouth double-blind clinical trial. ScientificWorld Journal [Internet]. 2015 [cited 2018 Feb 21]; 2015. Available from: https://www.hindawi.com/journals/tswj/2015/828794/.
23. Fürhauser R, Florescu D, Benesch $T$, Haas R, Mailath G, Watzek G. Evaluation of soft tissue around single-tooth implant crowns: the Pink Esthetic Score. Clin Oral Implants Res. 2005; 16(6): 639-44.

24. Zuhr O, Fickl S, Wachtel H, Bolz W, Hurzeler M. Covering of gingival recessions with a modified microsurgical tunnel technique: case report. Int J Periodontics Restorative Dent. 2007; 27(5): 457-63.

25. Zuhr O, Hürzeler M. Plastic-Esthetic Periodontal and Implant Surgery: A Microsurgical Approach. Surrey: Quintessence Publishing; 2012.

26. Ghanaati S, Booms P, Orlowska A, Kubesch A, Lorenz J, Rutkowski J, et al. Advanced platelet-rich fibrin: a new concept for cell-based tissue engineering by means of inflammatory cells. J Oral Implantol. 2014; 40(6): 679-89.

27. Ehrenfest DMD. How to optimize the preparation of leukocyte-and platelet-rich fibrin (L-PRF, Choukroun's technique) clots and membranes: introducing the PRF Box. Oral Surg Oral Med Oral Pathol Oral Radiol Endod. 2010; 110(3): 275-8.

28. Jamieson S. Likert scales: how to (ab) use them. Med Educ. 2004; 38(12): 1217-8.

29. Hirsch A, Brayer L, Shapira L, Goldstein M. Prevention of gingival recession following flap debridement surgery by subepithelial connective tissue graft: consecutive case series. J Periodontol. 2004; 75(5): 757-61.

30. Jankovic S, Aleksic Z, Klokkevold P, Lekovic V, Dimitrijevic B, Barrie Kenney $E$, et al. Use of platelet-rich fibrin membrane following treatment of gingival recession: a randomized clinical trial. Int J Periodontics Restorative Dent. 2012; 32(2): e41-50.

31. Karring $T$, Lang $N$, Löe $H$. The role of gingival connective tissue in determining epithelial differentiation. $J$ Periodontal Res. 1975; 10(1): 1-11.

32. Karring T, Östergaard E, Löe H. Conservation of tissue specifically after heterotopic transplantation of gingiva and alveolar mucosa. J Periodontal Res. 1971; 6(4): 282-93.

33. Bernimoulin J-P, Schroeder $H$. Changes in the differentiation pattern of oral mucosal epithelium following heterotopic connective tissue transplantation in man. Pathol Res Pract. 1980; 166(2-3): 290-312.

34. Chambrone L, Pannuti CM, Tu Y-K, Chambrone LA. Evidencebased periodontal plastic surgery. II. An individual data meta-analysis for evaluating factors in achieving complete root coverage. J Periodontol. 2012; 83(4): 477-90.

35. Zabalegui I, Sicilia A, Cambra J, Gil J, Sanz M. Treatment of multiple adjacent gingival recessions with the tunnel subepithelial connective tissue graft: a clinical report. Int J Periodontics Restorative Dent. 1999; 19(2): 199-206.

36. Cheung WS, Griffin TJ. A comparative study of root coverage with connective tissue and platelet concentrate grafts: 8month results. J Periodontol. 2004; 75(12): 1678-87.

37. Chambrone L, Sukekava F, Araújo MG, Pustiglioni FE, Chambrone LA, Lima LA. Root-coverage procedures for the treatment of localized recession-type defects: a Cochrane systematic review. J Periodontol. 2010; 81(4): 452-78.

38. Zucchelli G, Amore C, Sforza N, Montebugnoli L, De Sanctis $M$. Bilaminar techniques for the treatment of recession-type defects. A comparative clinical study. J Clin Periodontol. 2003; 30(10): 862-70.

39. Kerner S, Katsahian S, Sarfati A, Korngold S, Jakmakjian $\mathrm{S}$, Tavernier B, et al. A comparison of methods of aesthetic assessment in root coverage procedures. J Clin Periodontol. 2009; 36(1): 80-7.

40. Bouchard P, Malet J, Borghetti A. Decision-making in aesthetics: root coverage revisited. Periodontol 2000. 2001; 27(1): 97-120.

41. Rosetti EP, Marcantonio RAC, Rossa Jr C, Chaves ES, Goissis G, Marcantonio Jr E. Treatment of gingival recession: comparative study between subepithelial connective tissue graft and guided tissue regeneration. J Periodontol. 2000; 71(9): 1441-7. 
42. Bouchard P, Etienne D, Ouhayoun J-P, Nilvéus R. Subepithelial connective tissue grafts in the treatment of gingival recessions. A comparative study of 2 procedures. J Periodontol. 1994; 65(10): 929-36.

43. Dell N, Vaidyanathan V, Medhi I, Cutrell E, Thies W. "Yours is better!" participant response bias in $\mathrm{HCl}$. In: Proceedings of the SIGCHI Conference on Human Factors in Computing Systems [Internet]. 2012 (cited 2018 Feb 20): 1321-30. Available from: https://www.microsoft.com/en-us/research/ wp-content/uploads/2016/02/CHI2012-Dell-ResponseBias -proc.pdf.

44. Rotundo R, Nieri M, Mori M, Clauser C, Pini Prato G. Aesthetic perception after root coverage procedure. J Clin Periodontol. 2008; 35(8): 705-12.

\section{Do the CPD questionnaire on page 587}

The Continuous Professional Development (CPD) section provides for twenty general questions and five ethics questions. The section provides members with a valuable source of CPD points whilst also achieving the objective of CPD, to assure continuing education. The importance of continuing professional development should not be underestimated, it is a career-long obligation for practicing professionals.

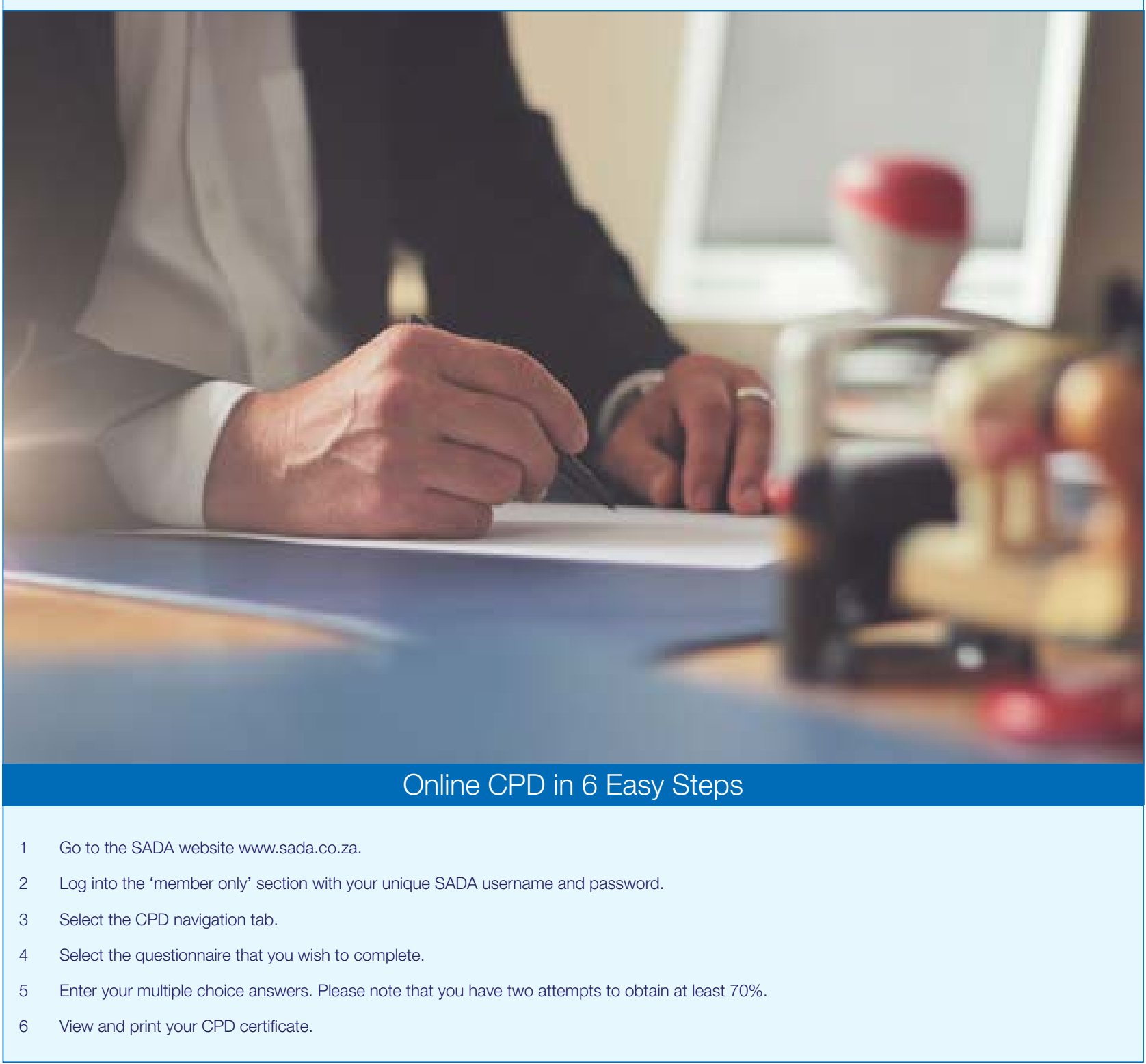

